\section{PALABRAS E IMÁGENES DE MUJERES EN EL PARTIDO SOCIALISTA: LA CAMPAÑA PRESIDENCIAL DE 1916 EN ARGENTINA ${ }^{1}$ \\ WOMEN'S WORDS AND IMAGES IN \\ THE SOCIALIST PARTY: THE PRESIDENTIAL \\ CAMPAIGNS OF 1916 IN ARGENTINA}

\section{SILVANA PALERMO •}

Investigadora Adjunta del CONICET con sede en el Instituto de Ciencias de la Universidad Nacional de General Sarmiento, Argentina.

E-mail: palermosilvi@gmail.com

\section{Resumen}

Este estudio examina la participación de las mujeres en las actividades proselitistas del Partido Socialista, en particular en la campaña presidencial de 1916. Se basa en el análisis de documentación partidaria y de dos importantes semanarios ilustrados de la época: Caras y Caretas y Fray Mocho. Argumenta que la notable capacidad de movilización del PS obedece a su experiencia de participación en el espacio público y electoral, ámbitos en los que las mujeres exhibieron un protagonismo incontestable, y también al hecho de que la prensa comercial se convirtió en un medio apropiado para transmitir el mensaje del PS, hacer conocer las palabras y los rostros de las mujeres socialistas.

\section{Registro bibliográfico}

PALERMO, SILVANA «Palabras e imágenes de mujeres en el Partido Socialista: la campaña presidencial de 1916 en Argentina", en: ESTUDIOS SOCIALES, revista universitaria semestral, año XXVIII, n 55, Santa Fe, Argentina, Universidad Nacional del Litoral, julio-diciembre, 2018, pp. 121-146.

\section{Abstract}

This study examines women's participation in the electoral campaigns of the Socialist Party, in particular the presidential campaign of 1916 . This analysis is based on a variety of sources: official documents from the Socialist Party, the Socialist press and two popular magazines, Caras y Caretas and Fray Mocho. This article argues that the notorious strength demonstrated by the Socialists to mobilize owes to their previous experience in electoral and public participation, in which women played a vital role, and also due to the fact that the commercial press became a prominent mean of communication of the Socialist creed, an appropriate instrument to make socialist women's words and faces know to a larger public.

\section{Descriptores · Describers}

Partido Socialista / Campaña electoral / género / Juana María Begino

Socialist Party / electoral campaign / gender / Juana María Begino

Recibido: 31/05/2018 Aprobado: 16/07/2018

\footnotetext{
${ }^{1}$ Agradezco a los coordinadores del dossier Francisco Reyes y Juan Buonuome y al arbitraje anónimo por las sugerencias y comentarios a la versión inicial.
} 
Una vez aprobada la ley Sáenz Peña, el Partido Socialista (PS) no escatimó esfuerzos para alcanzar con su prédica a aquellos varones que, a partir de entonces, se encontraron obligados a ejercer sus responsabilidades cívico-electorales. Dado que la ley garantizó la ciudadanía política sólo a los hombres, podría suponerse que las campańas electorales constituyeron, por definición, un ámbito varonil. ¿Participaron las mujeres en las actividades proselitistas? ¿Quiénes y en qué términos se involucraron? Para responder a estos interrogantes, este artículo examina la campaña realizada por el socialismo para la primera contienda presidencial regida por la nueva normativa, entre fines de i9i5 hasta el 2 de abril de 1916, fecha de los comicios.

Desde hace ya varias décadas, la historiografía dedica una atención creciente a la participación femenina en la vida pública y política. Aquí se aborda un aspecto aún insuficientemente explorado: el papel de las mujeres en aquellas prácticas y ámbitos propios de la política electoral en la Argentina de principios del siglo $\mathrm{xx}$. A partir de un estudio de caso, se propone aportar al conocimiento de las experiencias, prácticas y representaciones de la política electoral, desde una perspectiva de género. Es decir, se trata de problematizar cómo las concepciones sobre la diferencia sexual moldearon ese experimento político novedoso, que inauguró la ley electoral de 1912. ¿Contribuyó esta normativa a una masculinización de la vida política y pública en la Argentina de principios de siglo xx? La dimensión de género implícita en las normas electorales constituye un capítulo ineludible en los estudios sobre la conceptualización y construcción de la ciudadanía política en el mundo atlántico y en el análisis del modo en que las mujeres se construyeron a sí mismas como individuos y ciudadanos, a partir de las paradojas que suscitaba el reclamo a la igualdad de derechos en el reconocimiento de la diferencia (ROSANVALLON, I999; SCOTT, 20I2).

Desde el punto de vista prescriptivo, la llamada ley Sáenz Peña estableció la obligatoriedad y el carácter secreto del sufragio universal/masculino y dos leyes aprobadas previamente asignaron la tarea del empadronamiento al ejército y la justicia federal para evitar la manipulación electoral. Así, el ejercicio del derecho cívico y de la representación en materia de elecciones nacionales se ligó inexorablemente al servicio militar y, por tanto, la libreta de enrolamiento militar pasó a convertirse en "una carta de ciudadanía masculinizada» (VAlobra, 20IO: 3I). Las capacidades y virtudes para elegir y ser elegido se asociaron a las cualidades del individuo varón, apto para servir a su patria y dotado para optar de modo conciente, sin ataduras y acorde a sus intereses. La Gran Guerra no hizo más que 
reforzar la asociación entre masculinidad, servicio militar y ciudadanía, aunque su prolongación y la consecuente movilización del frente interno crearon condiciones de posibilidad para quienes, habiendo sido excluidos del ejercicio de las libertades políticas -en especial las mujeres-, la reclamaran precisamente en base a su colaboración con la causa nacional (JENSEN, 20I7).

La puesta en marcha del sistema político competitivo conllevó un menú amplio de prácticas, que iban más allá del acto comicial. En la vida partidaria, en general, y en las actividades proselitistas, en particular, las restricciones establecidas por las normas electorales no necesariamente eran efectivas. Dado que la competencia electoral requería difundir el mensaje partidario entre un público amplio, vale interrogarse sobre la participación en esa labor de quienes podían estar inhabilitados para el ejercicio del sufragio y la representación. Si bien esta cuestión amerita contemplarse para cada uno de los partidos que compitió bajo este nuevo régimen electoral, es particularmente pertinente para el caso del $\mathrm{PS}^{2}$. En efecto, desde sus inicios el socialismo hizo suya la defensa de las mujeres, en tanto trabajadoras y ciudadanas, y éstas gozaron de plena igualdad de derechos en la vida partidaria. Contamos con investigaciones que se concentran en el surgimiento de organizaciones femeninas, sus acciones en favor de los derechos civiles, laborales y cívicos, y la relación entre socialismo y feminismo (BARRANCOS, 2005 y 2007; BECERRA, 2009; LAVRIN, I995; RAITER, 2004; RAY, 2008). No obstante, el involucramiento de las mujeres en las actividades proselitistas del Ps resulta menos conocido.

En verdad, nuestro escaso conocimiento sobre los sujetos dedicados a esos trabajos electorales comprende tanto a las mujeres como a los hombres. Recién en los últimos ańos, al calor de enfoques de la historia socio-cultural y fruto de la renovación de la historia política, se han priorizado temas referidos a los usos políticos del espacio público y la vida electoral en la Argentina de fines del siglo xIX y mediados del siglo xx. En este marco, surgió el interés por el estudio de las campañas electorales, las cuales, al situar en el centro del análisis a los protagonistas y prácticas de la vida electoral, contribuyen a enriquecer nuestra comprensión de la relación entre sociedad y política. Algunas indagaciones recientes sobre campañas electorales en tiempos de la república democrática y conservadora demuestran su potencial para explorar las lealtades e identidades partidarias, la construcción de

\footnotetext{
${ }^{2}$ Sobre las mujeres en la Unión Cívica Radical, véase GALLO (2001).
} 
liderazgos, las formas de movilización popular, la propaganda y su financiamiento e inclusive la violencia política (GONZÁLEZ ALEMÁN, 2OI4; HOROWITZ, 2OI5; VALDÉZ, 2012 y 20I4).

Con el propósito de abordar la participación femenina en la primera campaña presidencial del ps bajo la ley Sáenz Peña, la primera sección se detiene en las formas de participación en la vida pública y electoral del socialismo en la experiencia partidaria previa a la contienda presidencial de 1916, a partir de la información brindada por el semanario ilustrado Caras y Caretas ( $C y C)$. El segundo apartado se concentra en la campaña presidencial, en base al examen de las versiones taquigráficas del XIV Congreso Nacional y el diario La Vanguardia ( $L V$ ). La última sección retoma el análisis de las noticias que algunos magazines, en particular $C y C y$ Fray Mocho (FM), ofrecieron respecto al protagonismo femenino en las actividades proselitistas del Ps. Nacidos en octubre de I898 y mayo de I9I2 respectivamente, estos semanarios ligaron el periodismo a la imagen de una manera novedosa y sin precedentes, al privilegiar la narración gráfica de los hechos. Dirigidos a un público que reconocían con intereses variados, ambos sobresalieron por sus tiradas masivas. A comienzos de siglo xx, $C y C$ rondaba los 70.000 ejemplares y pasaría los 100.000 en tiempos de los festejos del Centenario. Por su parte, la tirada de $F M$ se estima en 80.000 ejemplares (EUJANIAN, I999; ROGERS, 2008). Mientras que $L V$ constituye un punto de referencia ineludible, la selección de estos semanarios ilustrados obedece a diversas razones. Como hemos explorado en otro lugar, estas revistas se mostraron particularmente sensibles a la hora de cubrir los acontecimientos de la vida política nacional en las primeras décadas del siglo xx y devienen, por tanto, fuentes fecundas para interrogarnos sobre los protagonistas y características de las campañas electorales (PALERMo, 2018). Sabemos, asimismo, que sus páginas dotaron de una indudable visibilidad a las mujeres, al poner en circulación y discusión múltiples representaciones de la feminidad y reconfigurar los límites entre lo público y lo privado, lo íntimo y lo doméstico. Apelaron a las mujeres, en tanto lectoras y consumidoras, y las convocaron también en su condición de escritoras, en el marco de un proceso de profesionalización del periodismo en la Argentina de principios del siglo $\mathrm{xx}$ al que, sin duda, estas revistas contribuyeron (ARIZA, 2009; KIRKPATRICK, I99O NEWMAN, I99O; QUEIROLO, 20I6; TOSSOUNIAN, 2OI3).

Argumentaremos que el afianzamiento público y político del socialismo entre fines del siglo XIx y principios del siglo xx, especialmente en la ciudad de Buenos Aires, permitió no sólo a los hombres sino también a las mujeres participar de 
un diverso menú de eventos y celebraciones: veladas, conferencias, festejos, mítines, demostraciones de protesta, desfiles, cortejos. En éstos, muchos hombres y también varias mujeres adquirieron una experiencia de militancia, movilización y organización colectiva. No pocas de ellas, inclusive, se iniciaron en el oficio de oradoras. Y, como se verá, sus voces y rostros fueron amplificados por algunos de los semanarios ilustrados más populares de esas primeras décadas del siglo xx, lo cual acercó el mensaje de los y las socialistas a públicos más amplios. A su turno, esa experiencia adquirida y la repercusión de la acción femenina socialista en esas revistas contribuyeron al despliegue proselitista que el PS sostuvo afanosamente en la campaña presidencial de 1916 y a su incontestable visibilización publica.

\section{LAS MUJERES EN LA VIDA PÚBLICA Y ELECTORAL DEL PS A COMIENZOS DE SIGLO XX}

En la Argentina de comienzos del siglo xx, el ps adquirió una presencia cada vez más notoria, especialmente en una Buenos Aires en franca expansión. cyc documentó ese creciente protagonismo en las instancias más diversas y, casi sin excepción, al referirse a ellas subrayó la participación femenina. Fiel a su estilo periodístico, sus artículos visibilizaron a las socialistas apelando a un lenguaje llano y un generoso número de fotografías. Sus páginas las exhibieron entre el público asistente a actos y veladas, en tanto conferencistas o representantes en los órganos partidarios. De igual manera, registró que la cuestión de la mujer constituía un tópico fundamental en el discurso partidario, atento a los reclamos de mejores condiciones de trabajo y de vida para los hombres y mujeres trabajadoras (LOBATO, 20I8).

La cobertura de las celebraciones socialistas del $\mathrm{I}^{\mathrm{o}}$ de Mayo en Buenos Aires constituye uno de los ejemplos mejor conocidos. A comienzos de siglo xx, los denodados esfuerzos de los socialistas lograron que esta conmemoración, restringida a reuniones acotadas, pasara a consolidarse en la forma de «desfiles callejeros ritualizados» en la ciudad capital (REYES, 2OI6a). A esto contribuyó, sin duda, la presencia femenina, en particular, y de las familias, en general. Así, por ejemplo, durante el picnic organizado para celebrar el día del trabajo en i896, Luisa Pizza, hija de un reconocido militante socialista, instó al auditorio a abrazar la causa partidaria. Finalizada la reunión, los asistentes marcharon hacia el local del Vorwärts, donde se cerró el acto con una velada nocturna (BARRANCOS, 1994). Tres años más tarde, la crónica de $c y c$ dedicada a la manifestación congregada en la Plaza Belgrano 
en conmemoración del I $^{\mathbf{0}}$ de Mayo describía una situación similar. Destacaba la presencia de "animosas obreras» ataviadas para la ocasión, algunas en compañía de sus compañeros y otras simplemente solas. Asimismo, subrayaba el hecho de que, desde la tribuna, Cecilia de Baldovino «expusiera los ideales socialistas desde el punto de vista femenino» ${ }^{3}$.

Aún en un clima político menos distendido, como aquel de los primeros años del siglo $\mathrm{xx}$, la presencia de las mujeres, entre participantes y oradores del $\mathrm{I}^{\mathrm{O}} \mathrm{de}$ Mayo no se revirtió. En I9O2, los socialistas se congregaron en la Plaza Constitución a las dos de la tarde y desde allí se encaminaron hacia la Plaza Rodríguez Peńa. Encabezó la columna la Comisión Directiva del Partido junto al recientemente creado Centro Socialista Femenino (CSF). Como se sabe, éste se había fundado en abril de ese mismo año, a iniciativa de las hermanas Chertkoff (Fenia, Adela y Mariana), Justa Burgos Meyer y Raquel Messina -ambas docentes y defensoras de la educación laica- y Gabriela Laperrière de Coni, bien conocida por su labor a favor de la legislación de protección al trabajo femenino. A ellas se sumarían otras, por entonces más jóvenes, como Alicia Moreau y Carolina Muzzilli. Esta suerte de debut público del CSF gozó de un marco propicio. Al acto asistieron casi 5000 personas, quienes escucharon la palabra de dirigentes del partido y también de Baldovino, responsable según la crónica de una «bella disertación acerca del trabajo de la mujer y de los niños en la república» ${ }^{4}$.

$\mathrm{Al}$ año siguiente, Baldovino propiciaría la creación de la Unión Gremial Femenina. Como lo había hecho el CSF, ésta hizo su primera aparición pública en un acto del $\mathrm{I}^{\circ}$ de Mayo. Ese día, según la crónica de $c y c$, una multitud se reunió en la Plaza Constitución y agregó que:

«La Unión Gremial Femenina y el Centro Socialista de mujeres, como siempre, no sólo presentaban un contingente crecido y por lo mismo atraían todas las miradas, sino que los trajes claros de las obreras, luciendo vistosamente en el conjunto, imponían su nota pintoresca sobre el resto del compacto cuadro" ${ }^{5}$.

3 «El primero de mayo en Buenos Aires», CyC 06/05/1899, n.31.

4 «El primero de mayo. Las manifestaciones de los socialistas y anarquistas», CyC, 10/05/1902.

5 «El primero de mayo de Buenos Aires. El meeting de los socialistas», CyC, 09/05/1903. 
Al llegar a la Plaza del Congreso, luego de que varios oradores dirigieran la palabra, una comisión que integraba Baldovino hizo entrega de un pedido en favor de la sanción legislativa del proyecto de reglamentación del trabajo de las mujeres en las fábricas.

Más allá de las celebraciones del I ${ }^{\circ}$ de Mayo, en otras ocasiones, los y las socialistas saldrían a las calles. Como ha explicado F. Reyes, en la Argentina de fines del siglo XIX y las primeras décadas del siglo $\mathrm{xx}$, las manifestaciones «constituyeron un elemento medular y una forma perdurable de la práctica política socialista» (REYES, 20I6b: 17). Varias de esas demostraciones tenían por objeto reclamar mejoras en las condiciones de trabajo y de vida de las familias trabajadoras. Así lo ilustra la organización del multitudinario mitin en favor de los desocupados, con el propósito de incitar a los poderes públicos a tomar medidas tales como la creación de una oficina de trabajo, un censo de desocupados y la prohibición del trabajo de menores en fábricas y talleres (ROJKIND, 2008/2009). Por otra parte, cabe señalar que a comienzos del siglo xx las huelgas no se restringían a los ámbitos laborales, sino que, para poder concretarse, exigían de un despliegue espacial más amplio. Interrumpir las actividades en el mundo del trabajo resultaba demandante, se requería organizar asambleas (en espacios cerrados, pero también públicos), manifestaciones y mítines, que aseguraran la efectiva suspensión del trabajo y la solidaridad con la causa de los huelguistas. En esas instancias, por lo general, se hicieron presentes las mujeres (LOBATO y PALERMO, 2OII).

Un amplio menú de actos ligados al compromiso internacionalista y anti-militarista del ps potenció la presencia de las mujeres en el espacio público. Idéntico efecto tuvo la discusión atinente a los derechos civiles femeninos, en particular los proyectos sobre divorcio. A principios de I900, los socialistas se movilizaron en favor de la firma de tratados con Chile, apoyando el desarme y condenando las guerras $^{6}$. En 1904 denunciaron públicamente la represión de la que habían sido víctimas los trabajadores chilenos de Valparaíso. Una fotografía que acompañaba el artículo sobre esta demostración indicaba: «Sociedad Feminista acudiendo a la cita» ${ }^{7}$. Una vez más Baldovino ofició como oradora en dicho acto. En otra ocasión, al cumplirse el primer aniversario de la muerte de Jean Jaures, correspondió al CSF emprender una velada que contó con una nutrida concurrencia de hombres

\footnotetext{
6 «En Pro de los pactos con Chile la manifestación de los socialistas», CyC, 28/06/1902.

7 «La manifestación obrera contra los sucesos de Valparaíso», CyC, 13/06/1904.
} 
y mujeres. Y, a raíz de las manifestaciones en favor del proyecto de divorcio, realizadas en Plaza Lorea en septiembre de 1902, los socialistas brindaron su apoyo con discursos de Adrián Patroni y Palacios y las socialistas se encolumnaron con el grupo de «damas» que participaban de la demostración ${ }^{8}$.

¿Qué ocurría con las contiendas electorales? Como se sabe, el socialismo participó en las elecciones desde su fundación, limitándose, en sus inicios, a presentarse a aquellas para legisladores del distrito porteño. Los magros resultados de los primeros tiempos se tornaron auspiciosos en el contexto de disputas y fragmentación del partido de gobierno. En este clima, en el que no casualmente se ensayó la reforma que había establecido la circunscripción uninominal, el ps obtuvo su primer logro resonante: la llegada del Dr. Palacios a la Cámara de Diputados. En esa primera década del siglo xx, las campañas del ps adquirieron contornos propios y visibilidad, al menos en la Capital Federal. Estas requerían una intensa labor: elección de candidatos, propaganda oral y escrita, campañas en favor de la inscripción de los electores en los registros cívicos y la naturalización de los extranjeros (BERENSZTEIN, I99I; POY, 20I5 y 20I7).

Las socialistas no permanecieron ajenas a estos febriles trabajos electorales. Al recuperar su protagonismo se aprecia el esfuerzo de movilización que implicaban las campañas para el Ps, un partido pequeño y carente de recursos. Un esfuerzo que, sin embargo, se beneficiaba de la experiencia que aquel estaba construyendo en materia de movilización pública. Es decir, las formas de protesta y las celebraciones públicas de los socialistas contribuían y, a su turno, se retroalimentaban por la efervescencia de las contiendas electorales. Así, la reconstrucción de las formas de participación femenina permite advertir cómo se enhebraron las prácticas propias de la vida pública partidaria con aquellas de la vida electoral. En esa retroalimentación se comprende la capacidad exhibida por el ps para el despliegue proselitista, tanto en la Capital como en otras localidades del país en los meses que ocupó la campańa presidencial de i9ı6.

Atenta la política electoral, $C y C$ narró al detalle los comicios. Sobre las elecciones de diputados por la Capital en 1904, por ejemplo, publicó una nota que destacaba que, pese a que algunos candidatos habían organizado fiestas para convidar con asado y cerveza a sus electores, había sorprendido el «chaparrón» de libretas socia-

8 «Los meetings de la semana por el descanso dominical y en favor del divorcio», CyC, 06/09/1902. 
listas9. La nutrida manifestación realizada para celebrar el triunfo de Palacios en la parroquia de San Juan Evangelista mereció una fotografía. Igualmente, una de las instantáneas dedicadas a la febril actividad en las parroquias porteñas se detenía en la de Balvanera, donde podían verse los «propagandistas femeninos del candidato socialista Juan B. Justo, que usaban como distintivo un clavel rojo». Por su parte, a propósito de la campaña electoral de principios de 1906, la crónica de cyC exhibía al Dr. Palacios recorriendo en carro las calles de la circunscripción $4^{\mathrm{a}}$, asistido por «mujeres socialistas haciendo propaganda en la Boca ${ }^{10}$. La narrativa del acto comicial insistía también en que «los socialistas ayudados por el elemento femenino, marchaban con su leader Palacios, a la cabeza, haciendo votar a sus correligionarios ${ }^{11}$.

Por cierto, la intensidad de la vida electoral no se agotaba en los comicios. La expectativa ante los resultados y las certezas de la existencia de fraude mantuvo activos a los socialistas. En protesta a raíz de la malversación electoral cometida en las elecciones de 1908, el ps convocó a una demostración para el último domingo del mes en Plaza Lorea, desde donde partieron en manifestación por Avenida de Mayo hasta Plaza Colón. Se destacó que «a la cabeza de la manifestación iba un grupo generoso de señoras y señoritas, las cuales aportaban también sus gritos entusiastas». Varios oradores cerraron el mitin, instando a que las elecciones se declararan nulas ${ }^{12}$. En otros casos, era la labor parlamentaria socialista la que se veía reforzada por la acción de movilizaciones callejeras. Así, por ejemplo, en favor del proyecto de creación de mil escuelas promovido por el partido, el csF organizó en la Plaza Congreso un mitin en el que el diputado Enrique Dickmann explicó los alcances de la propuesta parlamentaria y, en representación del Centro, dirigió la palabra Juana María Begino ${ }^{13}$.

No sorprende que Begino se desempeñara allí como una de las oradoras, pues se trataba de una militante atenta a temas de educación e infancia. Había presentado un trabajo en el Primer Congreso Internacional Femenino de I9IO, sobre la mujer trabajadora y la educación de los hijos, en el que criticaba el concepto de caridad y defendía la implementación de una ley protectora del trabajo femenino

\footnotetext{
9 "Las elecciones nacionales», CyC, 12/03/1904.

10 Sobre la campaña de 1904, cf. CARUSO (2018).

11 «La elección de diputados», CyC, 14/03/1906.

12 «El meeting de los socialistas», CyC, 21/03/1908.

13 «Meeting del Partido Socialista para apoyar el proyecto parlamentario pro-creación de mil escuelas», CyC, 04/09/1915.
} 
(LAVRIN, I995: 85-86). Asimismo, había elogiado la labor del Congreso Nacional del Nińo, en un artículo publicado en $C y C$, donde destacó la iniciativa de la Liga de los Derechos de la Mujer y del Niño - organizadora del congreso- y subrayó la capacidad de su comité ejecutivo, integrado por Julieta Lanteri Renshaw y Raquel Camaña, entre otras, a quienes calificó como «mujeres inteligentes, estudiosas y buenas», capaces de contribuir al «engrandecimiento de la patria, dándole mayor número de ciudadanos útiles» ${ }^{14}$.

\section{LA DELEGADA Y CONFERENCISTA JUANA BEGINO EN LA «GRAN CAMPAÑA NACIONAL»}

Entre el 9 y el II de julio de I9I5, el ps llevó adelante su II Congreso Extraordinario (xIv Congreso Nacional) en la ciudad de Buenos Aires. Los temas a discutir auguraban intensos debates: la expulsión de Palacios, la posición ante la Gran Guerra y la concurrencia a la elección presidencial. Al Congreso enviaron representantes todos los centros socialistas que cumplieron con los requisitos estatutarios. En la nómina de las secciones constituyentes se encontraba el CSF, cuya delegada fue Juana Begino. Juana C. de Colombo, la única otra mujer que integraba la nómina de representantes figuraba, al parecer, en carácter de suplente.

Al inicio de sus sesiones, el Congreso abordó la separación de Palacios del ps, quien había solicitado la reconsideración de esa medida. Tras momentos de intensa confrontación, se decidió, por mayoría de votos, mantener la sanción disciplinaria, que alejaría definitivamente a Palacios para convertirlo en el fundador del Partido Socialista Argentino ${ }^{15}$. El csf se contó entre los centros que se opusieron al recurso de apelación interpuesto por Palacios. A raíz de esta controversia, luego de dar la bienvenida a los «camaradas» del interior, Begino instó a proceder acorde lo establecido por las normas del estatuto partidario y conforme lo decidido por la comisión directiva. Esta coincidencia del CSF con las autoridades y el bloque partidario se reiteraría al tratar la participación del ps en la contienda presidencial con candidatos propios. Al llegar el domingo, el Congreso se abocó a discutir esta cuestión, bajo la presidencia de E. Del Valle Iberlucea y Begino como secretaria.

\footnotetext{
14 Juana María Begino, «El Congreso Nacional del Niño. La «Liga para los derechos de la mujer y del niños y sus trabajos», CyC, 16/11/1912.

${ }^{15} \mathrm{Al}$ respecto, ver el trabajo de Carlos Herrera incluido en este dossier.
} 
La intensa controversia que se suscitó al respecto evidenciaba, como ha señalado R. Martínez Mazzola, las ambivalencias del Ps ante la ley electoral de I9I2 (MARTÍNEZ MAZZOLA, 20I5). En efecto, ante la participación con candidatos propios en la primera elección presidencial que se llevaría a cabo conforme a esta normativa, los socialistas se debatieron entre la aprensión y el optimismo.

La negativa de algunos delegados a la participación del ps en la contienda presidencial nacía de una cuestión de principios: un radical rechazo a las instituciones políticas «burguesas». A esto se sumaba la incertidumbre que auguraba la implementación de la nueva normativa electoral. ¿Qué decisión adoptarían los electores del ps en el Colegio Electoral? ¿Contemplarían una alianza con otro partido y votarían a un candidato «burgués»? Las suspicacias generadas por situaciones difícilmente previsibles potenciaron la desconfianza basada en objeciones doctrinarias. Estos escenarios imaginados, fruto de la especulación, terciaron a la hora de anteponer reparos y reclamar una toma de posición clara e inamovible por parte de la comisión directiva y el grupo parlamentario del partido.

Aquellos que desempeñaban o aspiraban a cargos electivos, en esa coyuntura electoral favorable que el ps atravesó en la primera mitad de la década de ı9ıo, argumentaron a favor de participar en la elección presidencial con candidatos propios. En tal sentido, se manifestaron Adolfo y Enrique Dickmann y Antonio de Tomaso. Con matices, sus argumentos coincidieron en aludir a cuestiones de principio y razones tácticas. Desde su perspectiva, si el ps había defendido la participación electoral desde su fundación, no cabía ahora sumarse al «detestable ejemplo de la abstención», en palabras de E. Dickmann. Por otra parte, tras casi veinte años de honrar ese principio, cabía reconocer que el ps había suscitado la lealtad de un buen número de votantes. En consecuencia, el ps debía honrar su compromiso ante los muchos que habían genuinamente depositado su confianza en él. De Tomaso discurrió sobre este punto e insistió en que participar en esas elecciones presidenciales era tanto una cuestión de principios como «un deber, diré así, de lealtad para con nuestros electores» (PARTIDo socialista, I9I5: 334).

Otra razón para nada menor consistía en que, al competir con una formula propia en la contienda por la presidencia, el ps se permitía aprovechar una oportunidad que, a los ojos de muchos de sus dirigentes, no podía desperdiciarse. Una campaña presidencial abría las puertas a una audiencia amplia, integrada por aquellos militantes y simpatizantes, así como por quienes desconocían el credo socialista. Las expectativas, en tal sentido, eran por demás ambiciosas. De Tomaso 
sostuvo: «tendremos la oportunidad de hacer por primera vez -por el carácter mismo de la elección, con candidatos únicos y con una sola plataforma electoral para toda la republica - una gran campaña nacional» (PARTIDO SOCIALISTA, I9I5: 333, destacado propio).

Begino, intervino apenas iniciada esta discusión. Sostuvo que, «interpretando el deseo de mi centro", favorecería la participación del ps en las elecciones presidenciales con candidatos propios. Apelando a su diferencia, es decir a su condición femenina, se permitió dotar a su disertación de una «nota de sentimentalismo». No discurriría sobre disquisiciones doctrinarias ni de estrategia partidaria sino que, por el contrario, optó por una alocución breve pero vigorosa, centrada en denunciar la brecha existente entre la imagen edulcorada de una nación próspera, hospitalaria y promisoria y las desalentadoras experiencias cotidianas de las familias trabajadoras. Para Begino, el ps debía participar con candidatos propios en la elección presidencial para denunciar a un país que:

«Cifra su orgullo nacional en tener buques de guerra mientras el pueblo se muere de hambre condenado a permanecer con los brazos inermes, en una desocupación forzosa que lo lanza a la calle dispuesto a engullir el plato de comida con que -ya sea en la forma de las famosas ollas populares, o ya en la del no menos famoso pan bazo radical- se pretende calmar su hambre, colocándosele en la dolorosa, en la cruel situación de tener que abandonar su hogar, que creía al abrigo de todas las tempestades de la vida para ir a hacerse matar en los campos de la colosal guerra europea, porque nuestro gobierno ha hecho del nuestro un país absolutamente inhospitalario al no preocuparse, como no se preocupa de mejorar las condiciones de vida de la clase trabajadora» (PARTIDO SOCIALISTA, I9I5: 323-324).

Sus referencias a esta crítica situación incluyeron además el «despojo de los trabajadores del campo», la vigencia de leyes de Residencia y de Defensa Social, la existencia de leyes impositivas que gravan «el consumo y los artículos de labor», el "porcentaje enorme de analfabetos en el país», pese a la disponibilidad de recursos que, a su juicio, se malgastaban en «una innumerable turba de zánganos de sotana» (PARTIDO SOCIALISTA, I9I5: 324).

$\mathrm{Su}$ «sentimentalismo» no era banal, ni sería intrascendente, ya que anticipó el tema que privilegiaría el ps en la campaña: el deterioro de las condiciones de trabajo y de vida de la clase trabajadora en la coyuntura recesiva provocada por 
la Gran Guerra a ambos lados del Atlántico ${ }^{16}$. Y en ese terreno, el Ps reprobaba tanto las representaciones autocomplacientes de la elite gobernante del Centenario como el llamado «obrerismo radical», esto es, las propuestas de la UCR en favor de los menos favorecidos. Se vislumbraba una dura y, en ocasiones, irreconciliable disputa en torno a las políticas a implementar en materia laboral y social que, como se sabe, continuaría durante el curso de la república democrática.

La batería de argumentos a favor de la participación en la elección presidencial con candidatos propios rindió frutos, pues, finalmente, esta propuesta logró ser aprobada por una significativa mayoría. Hacia finales de 1915, el partido se lanzó a las actividades proselitistas, que se intensificaron en los primeros meses de i9I6. Fueron días demandantes para todos los hombres y también las mujeres del ps. Una vez más Begino sobresaldría en esta empresa por su afanosa labor. En efecto, a medida que avanzaba el verano, el circuito de conferencias en teatros, bibliotecas y centros partidarios se multiplicó. De igual manera, proliferaron los mítines en las plazas y esquinas de barrios de las grandes ciudades, en particular en la Capital Federal (PAlermo, 20I6). Las actividades proselitistas se concentraban de miércoles a domingo. Durante los días de semana, las conferencias eran por lo general nocturnas, de modo que el público trabajador pudiera asistir, mientras los sábados y domingos solían organizarse jornadas vespertinas. Así, por ejemplo, una de esas tardes de principios de diciembre de I9I5, Begino se desempeño como oradora, junto a Del Valle Iberlucea y Enrique Dickmann en un acto organizado por el comité electoral de Nueva Pompeya. Según informó $L V$ un numeroso público se había reunido para escuchar las disertaciones dedicadas al tema de la separación de la iglesia del Estado ${ }^{17}$.

Begino dio numerosas conferencias sobre aquellos temas que había enumerado en su alocución en el Congreso. En ocasiones, el foco recayó sobre los derechos femeninos. A comienzos de diciembre dictó una conferencia titulada «La mujer y el socialismo", auspiciada por el comité de la circunscripción $19^{a}$. Junto a ella, disertaron E. Dickmann y Alberto Iribarne, quienes se ocuparon de temas presu-

${ }^{16}$ Qué temas devienen nodales en una campaña es una de las cuestiones que, según los especialistas, requiere ser objeto del análisis histórico. Respecto a la centralidad de la Gran Guerra y la reforma social en la elección presidencial de 1916 en Estados Unidos, ver SANDERS (2015).

${ }^{17} L V, 05 / 12 / 1915$. 
puestarios y de la acción socialista ${ }^{18}$. La selección de oradores, los temas abordados y el público que concurrió a la cita revelaban que hombres y mujeres compartían las actividades proselitistas del ps. Begino no se limitó a dar conferencias organizadas por y para el CSF. Cabe reconocer, asimismo, que dicho centro patrocinó todo tipo de actividades, no sólo aquellas encabezadas por mujeres o restringidas a temas femeninos. Así, una noche de viernes se invitó a dos conferencias, la primera, en el centro de la circunscripción $\mathrm{II}^{\mathrm{a}}$, tuvo como anfitriona a la Sra. Agustina Teixeira, quien presentó a los disertantes: José Mouchet y Guido Cartey; la otra, realizada en la sede del CSF, contó como oradores a Antonio Zaccagnini y Alfredo Spinetto, bienvenidos por Beatriz Chizarroni ${ }^{19}$. Por último, cabe destacar que, en ocasiones, eran conferencistas varones quienes se ocupaban de temas que claramente competían a las mujeres, en especial a las trabajadoras, como la conferencia de Del Valle Iberlucea sobre el trabajo a domicilio, que se celebró en el Cine General Mitre un miércoles por la noche. Su recaudación -las localidades se pusieron a la venta- se destinó a beneficio de la propaganda electoral ${ }^{20}$. Como se observa, en materia de conferencias y veladas, los hombres y mujeres socialistas compartían codo a codo tanto el estrado y la tribuna como la presencia entre el publico asistente. Si bien se observa que no protagonizaban estas actividades en idénticas proporciones, lo que importa resaltar aquí es el carácter relativamente igualitario de la participación femenina en términos de las tareas desarrolladas y el ejercicio de la actividad proselitista.

Otras actividades culturales y políticas también estaban concebidas para la participación de personas de ambos sexos e inclusive de distintas edades. Para reflexionar sobre educación, el Centro de la Juventud Socialista Carlos Marx convocó a una «conversación familiar» para tratar el tema de la religión ${ }^{21}$. Por su parte, los centros de Villa Devoto y Villa del Parque invitaron para el sábado a la noche en el local de la Sociedad Operai Italiana a un festival que incluía himnos, una conferencia de Del Valle Iberlucea sobre los ideales de la democracia obrera y cerraba con un gran baile familiar ${ }^{22}$. El propósito de este tipo de actividades

\footnotetext{
${ }^{18} L V, 08 / 12 / 1915$.

${ }^{19} L V, 10 / 12 / 1915$.

${ }^{20} L V, 15 / 12 / 1915$.

${ }^{21} L V, 10 / 12 / 1915$.

${ }^{22} L V, 11 / 12 / 1915$.
} 
era múltiple: conocer y reflexionar sobre los principios del socialismo constituía parte de un programa que se concebía como una actividad para toda la familia y bien podía combinarse con un momento de esparcimiento. Asimismo, todo podía convertirse en una buena excusa para reunir fondos para las actividades proselitistas.

Muchos hombres y también algunas mujeres participaron de las dos más grandes celebraciones de propaganda: el acto de proclamación de las candidaturas y el cierre de campaña. Ambos tuvieron lugar en la Capital y fueron cuidadosamente planificados. A menos de un mes del escrutinio, el 2 de marzo desde las 19.30 hs., bandas de música y coros del ps se reunieron sobre la calle Rivadavia, entre Riobamba y Andes, ejecutaron marchas sinfónicas y entonaron himnos obreros. Allí se ubicaron ocho tribunas con tres a cuatro oradores cada una. Entre estos se encontró naturalmente Juan B. Justo (no así el candidato a vicepresidente que se encontraba de gira en el Chaco), los candidatos a diputados nacionales por la Capital Enrique Dickmann, Basilio Vidal, José Penelón, Augusto Bunge, Fernando de Andreis, José Lemos e importantes legisladores, como el diputado Mario Bravo y el senador Del Valle Iberlucea. Aunque no estaba anunciada en el programa, Begino dirigió su palabra al público. Con una prédica encendida, puso el eje en la condición de la mujer y comenzó su alocución sosteniendo: «hablo en nombre de mi sexo, de mi sexo tan acerbamente excluido de los trascendentales problemas de la vida, por el egoísmo varonil». Reclamó para el PS la labor de transformar el Código Civil, que «nos envilece» y de pugnar por la aprobación de una ley de divorcio absoluto. En los tramos finales, condenó la guerra europea y auguró un triunfo partidario en los comicios de abril. Instó, por último, a los legisladores socialistas a merecer «la gloria de haber sido los primeros en ocuparse de la elevación de la mujer» ${ }^{23}$.

El viernes 3I de marzo, nuevamente en la Capital, el PS celebró el cierre de campaña. Fue un evento imponente, un mitin que, en rigor de verdad, consistió en un despliegue de varios encuentros en toda la ciudad. En los distintos puntos neurálgicos de los barrios se organizaron mítines, desde donde partieron las columnas de manifestantes -siete en total- hacia la plaza San Martín, para cerrar el acto por la noche a las 2I hs. Al parecer, las columnas llegaron a ocupar alrededor de 40 cuadras de la ciudad. El clima fue festivo, primó la informalidad, pese al esfuerzo de los organizadores de transformarlo «en una ostentación de fuerza y cultura» de la clase

${ }^{23} L V, 03 / 03 / 1916$. 
trabajadora. Se escucharon cánticos picarescos y se exhibieron figuras alegóricas y carteles con inscripciones humorísticas alusivas a los radicales ${ }^{24}$. Por supuesto, hubo tiempo para discursos encendidos. Entre los oradores figuraron los candidatos a presidente y vice-presidente, mientras algunos legisladores, como Del Valle Iberlucea, debieron hablar en dos oportunidades. Por su parte, Begino dirigió una vez más su palabra a la multitud, confirmando sus credenciales como oradora del partido.

\section{HOMBRES Y MUJERES SOCIALISTAS EN LOS SEMANARIOS ILUSTRADOS}

Los semanarios ilustrados de esos ańos - CyC, Fray Mocho y otros igualmente populares como $P B T$ o Mundo Argentino- cubrieron los vaivenes de la campaña presidencial de 19ı6. Ya desde la realización del XII Congreso Socialista, la revista $F M$ publicó una nota, ilustrada con fotografías sobre el interior y exterior del Salón Teatro de la calle Almirante Brown. Una de ellas enfocaba a Palacios a la expectativa de la decisión partidaria sobre su expulsión definitiva. Otra exhibió a algunos representantes de las secciones al Congreso en una informal charla en la acera, entre los que se encontraba la delegada del $\operatorname{CsF}^{25}$. En marzo de 1916 , dicha revista le dedicó una nota de una página, titulada: «De la campaña electoral: la conferencista Begino». Quien brindó la información para el artículo fue, según el propio redactor, un militante socialista. $\mathrm{Al}$ anunciar que traía información sobre una de las «más activas compañeras», la Sra. Begino, el periodista respondió: «ih!... ¿ la Sra. que habló en el gran mitin de la calle Rivadavia, el día de la proclamación?». El informante reafirmó: «La misma, ya saben ustedes que nosotros hemos sido los primeros en utilizar los servicios de la mujer en las campañas electorales. Nuestras compańeras los días de comicios, recorren las calles repartiendo boletas socialistas. Ya las verá usted el 2 de abril $»^{26}$.

La crónica cerraba con una alusión a la trayectoria de Begino, dando prácticamente por sentada su celebridad como conferencista. Se recordaba que Juana, oriunda de San Nicolás de los Arroyos, había fundado allí el Centro Cosmopolita Obrero en I898. Al escindirse en una rama ácrata y otra socialista, ella había per-

\footnotetext{
24 LV, 01/04/1916.

25 Red Jacket, "Congreso Socialista», FM, 16/07/1915.

${ }^{26}$ Rimac (pseudo.), «De la campaña electoral: La conferencista Juana Begino», FM, 24/03/1916.
} 
manecido fiel a esta última. Desde entonces no había abandonado la militancia socialista, que continuaría en Rosario. En referencia a su condición de escritora se informaba que ya había publicado "dos buenos libros», entre ellos «Mantos del corazón» y algunos poemas. Dos fotografías acompañaban la nota: su retrato y una imagen de Begino, de pie, disertando en un cine de la Capital. De este modo, su labor y militancia se hacían conocidas a un público más amplio que el estrictamente partidario.

La agitación electoral motivada por los primeros ensayos luego de la ley Sáenz Peña logró encontrar en otras mujeres propagandistas para la causa del ps. En otra nota publicada en $F M$, el periodista Félix Lima esbozaba la trayectoria de algunas de ellas, estrechamente vinculadas con dirigentes del partido. Podría pensarse que la visibilización del protagonismo de estas mujeres contribuía a la construcción discursiva de linajes partidarios, conformados en el curso de casi veinte años de vida política. Documentar la densidad de ese entramado, fortalecido a partir de redes de familia en las que las mujeres eran engranajes claves, no resultaba desatinado al dotar de carnadura a un partido que se exhibía, mediante la prensa de masas, a los ojos de quienes poco sabían sobre él. No obstante, estas mujeres no aparecían aquí como simple eslabón de una prosapia socialista. Más de dos páginas de información, acompañadas de varias fotografías, transmitían algo más sobre el socialismo y sobre aquellas mujeres identificadas con ese ideario. En especial, en tanto sus trayectorias no se ajustaban estrictamente a los propios modelos de representación femenina que primaban en algunos de esos mismos semanarios ilustrados: la madre benefactora, la joven consumidora o la escritora, a quien se representaba fundamentalmente en función de sus atributos femeninos y belleza antes que en la capacidad del ejercicio de su oficio (ARIZA, 2009).

En primer lugar, la selección de mujeres sobre las que se detenía la nota ponía de manifiesto la confluencia y el trabajo mancomunado de distintas generaciones. Esto comprobaba que el ps atesoraba ya una historia de hombres y mujeres militantes. Entre las de «la guardia vieja» -según las calificaba Félix Lima- se encontraba la Sra. Campodónico de Dickmann (esposa del por entonces diputado nacional), quien se había afiliado al partido en I899 y había pasado a dedicarse por entero al «cuidado de sus hijos». Otra de las precursoras, la Sra. Juana Villanueva de Mantecón, madre de «todos los Mantecón del partido» y «luchadora de los primeros tiempos» era calificada «una reliquia». Había oficiado de sub-administradora de $L V$, cuando su hijo se había responsabilizado de su administración y contribuido 
a fundar el CSF, cuya comisión integró varias veces. Asimismo, había participado en la formación de las sociedades de Alpargateras y Tejedoras y motorizado la organización de diversas actividades partidarias entre las que se contaban fiestas, conferencias y reuniones de propaganda electoral.

Entre las mujeres adultas, se mencionaba a Fenia Chertkoff de Repetto, quien dedicaba las horas libres que le dejaban «las múltiples ocupaciones de orden partidista» a la escultura. Se destacaba por sus iniciativas para organizar programas recreativos y educativos para nińos, junto a su hermana Mariana. En la lista de las más jóvenes, incorporadas a la lucha partidaria en tiempos de la efervescencia electoral, se encontraban Victoria, Eugenia y Elena Mauli, hijas de uno de los «decanos del partido». Asimismo, se incluía a Victoria Gukowsky de De Tomaso, esposa del «benjamín» socialista en la Cámara de Diputados, a quien se reconocía como una "conferencista de nota y una entusiasta propagandista de sus ideales». Carolina Muzzilli, de 25 años de edad y hermana del secretario de Palacios, recibía una mención especial, en tanto directora del periódico quincenal Tribuna Femenina. Se la caracterizaba como «la más vehemente y también la más revolucionaria» y, en otra ocasión, también $F M$ había hecho notar su desempeño como oradora de la multitudinaria manifestación en Plaza Lavalle en ocasión de la campaña para las elecciones de diputados en la Capital de marzo de $1914^{27}$.

En segundo lugar, la nota advertía que la militancia en el ps permitía a muchas mujeres adquirir una educación, desarrollar habilidades y capacidades de gestión, tentar un camino propio como conferencistas, escritoras e inclusive periodistas. El partido las dotaba de una formación que no se obtenía con facilidad en otros ámbitos. Así, afirmaba «en trece años de no interrumpida lucha, gracias al ejercicio de la secretaria del centro socialista por la cual han pasado muchas compañeras se transformaron en habilísimas secretarias. Algunas hoy redactan con facilidad manifiestos y otras hasta mojan en nuestros periódicos ${ }^{28}$. Los reveladores epígrafes de dos importantes fotografías de Muzzilli reforzaban esta afirmación. Una de sus fotos, sentada en un sillón con una gran biblioteca detrás, era acompañada por una leyenda que indicaba que estaba en su «habitación de trabajo y -acotaba- escribe a máquina». La otra fotografía la exhibía parada, junto a una rotativa "pasando revista a un ejemplar recién impreso».

\footnotetext{
27 «La manifestación socialista del viernes», FM, 27/03/1914.

${ }^{28}$ Félix Lima, «Mujeres socialistas», FM, 30/04/1915.
} 
Lima celebraba, en tercer lugar, la capacidad política de estas mujeres, lograda a partir de su organización colectiva en el seno del partido. Con minuciosidad, sintetizaba más de una década de labor del CSF, la participación femenina en protestas y manifestaciones, su incidencia en la creación del Departamento Nacional del Trabajo y en la legislación en favor de los derechos de las trabajadoras ${ }^{29}$. En tal sentido, las acciones individuales y colectivas de estas mujeres se encomiaban por su probado compromiso con el bien común y su estilo igualitario. El potencial transformador de su labor, indudablemente política, se acentuaba en la comparación con la obra de las mujeres aristocráticas: «Estas socialistas trabajan febrilmente por su causa llevando una vida muy distinta de lo que hacen las señoras y señoritas de alto copete ya sean vicentinas o del Divino Rostro ${ }^{30}$.

Es evidente que este reconocimiento a las mujeres socialistas nacía de una empatía política o afinidad cultural que, algunos artículos, reconocían explícitamente. Es verdad también que el interés por mostrar los rostros de los personajes de la política, sus prácticas partidarias y también su intimidad se correspondía con la finalidad de revistas, destinadas a un público diverso, que combinaban información con entretenimiento y prestaban atención a aristas de la política desestimadas en la cobertura de los grandes matutinos.

Por último, cabe advertir que la visibilización de la labor de algunas de estas mujeres parece haber surgido de cierta familiaridad entre ellas y los semanarios ilustrados, fruto de un vínculo construido en el ejercicio del oficio. Las publicaciones de algunas de ellas como escritoras así lo ilustran, corroborando esa coloquial y, sin duda sesgada, expresión de Lima: «algunas mojan en nuestros periódicos». De hecho, Begino encontró en esos magazines un espacio para la publicación de sus poemas, ensayos y artículos. Promotores del periodismo profesional, esos semanarios les brindaron a estas mujeres, al igual que a otros tantos hombres, una fuente de ingresos y una vitrina para su producción. E, inclusive, no dudaron en subrayar el valor de esa escritura femenina. Bajo el título de «novelista y peinadora», una nota de $C y C$ distinguía a Begino, argumentando:

${ }^{29}$ Félix Lima, «Mujeres socialistas», FM, 30/04/1915.

30 Félix Lima, «Mujeres socialistas», FM, 30/04/1915. 
«En estos tiempos de andante feminismo, que una mujer escriba una novela, ello, por cierto no importa mayor novedad de bulto. Tenemos escritoras por docenas. Pero que una peinadora escriba una novela en los ratos de ocio que le restan del trabajo manual, esto sí que es otro cantar y novedoso, sin duda. Tal es el caso de la escritora Juana María Begino, establecida con un taller de peinados y postizos en la ciudad de Rosario» ${ }^{31}$.

Según la crónica, los primeros oficios de Juana habían sido humildes, inclusive había trabajado como criada, pero «las lecturas la llevaron a otro campo de la lucha por la vida». Sin descuidar su taller, ni la educación de sus hijos, Juana había logrado publicar un guión dramático que la crítica teatral rosarina había elogiado y una novela, «Páginas del Corazón», prácticamente autobiográfica, en la que narraba «su propia existencia llena de dolores, sufrimientos y penurias» ${ }^{32}$. Al finalizar, ella confesaba que deseaba «escribir tan solo, pero mi situación modesta no me permitiría abandonar el taller de postizos. Y aquí me tiene usted haciendo drama y novela, en los momentos de descanso».

No se conoce al detalle la vida de Begino, más allá de las referencias que brindan estos artículos dispersos. Se casó con Ángel L. Beggino, un periodista y militante socialista quien, al igual que ella, se inclinaría por el socialismo independiente a fines de 1920 (TARCUs, 2007: 54) ${ }^{33}$. Ignoramos si pudo dejar su trabajo del taller, pero lo cierto es que publicó con regularidad poemas, ensayos y guiones cortos, en particular en $F M$ entre 1916 y 1930 («Mis Versos», «Alma mater» o textos cortos como "Exhorto», «Siluetas sociales», «El eterno femenino», «Camino torcido», entre otros) y se editaron algunas de sus conferencias, a las que se había dedicado con entusiasmo en el marco de las actividades proselitistas del partido, como «La mujer y el socialismo».

\footnotetext{
31 «Novelista y peinadora», CyC, 17/06/1911.

32 «Novelista y peinadora», CyC, 17/06/1911.

${ }^{33}$ El Diccionario Biográfico de la Izquierda Argentina (2007) consigna el apellido de Juana como Beggino. Aquí se ha optado por mantener Begino, pues así consta en todas las referencias de las diversas fuentes consultadas.
} 


\section{CONSIDERACIONES FINALES}

En el verano de 1916, al reseñar los actos de campaña de ese año, la prensa destacaba aquellos protagonizados por el Ps, tanto por su organización como por el sorprendente número de asistentes. En esta caracterización coincidieron importantes diarios de la capital como La Nación, los semanarios ilustrados y, naturalmente, las páginas de $L V$. Esta última definió al acto de proclamación de candidaturas como un "gran mitin" y estimó la asistencia en aproximadamente 50.000 personas ${ }^{34}$. Su cifra parecía abultada, aunque la revista $C y C$ confirmó esta impresión con fotografías que exhibían el numeroso público apiñado ante las distintas tribunas ${ }^{35}$. La descripción del cierre de campaña mereció calificativos similares. Independientemente de las estimaciones respecto a la asistencia, el diario La Nación lo calificó como uno de los «más numerosos que se hayan realizado en la actual campańa electoral» ${ }^{36}$.

¿Cómo explicar ese espectacular despliegue de un partido pequeño, falto de recursos y carente de una estructura sólida a escala nacional? A los pocos años, los propios dirigentes partidarios ensayaban una respuesta. Con la misma claridad que había argumentado a favor de la participación en la elección presidencial de I9I6, el diputado De Tomaso se explayaba en un artículo publicado en $F M^{37}$. A su entender, la clave estaba en la modernidad del Ps, su capacidad para abrazar y hacer un uso inteligente de las tecnologías comunicacionales de su tiempo. En tal sentido, subrayaba el indudable protagonismo de los diarios y periódicos socialistas -los muchos ańos de servicio prestados por $L V$ y el nuevo diario de la tarde $L a L u c h a-$, la edición de libros y folletos y la eficacia de los afiches partidarios ${ }^{38}$. Se preciaba, asimismo, de la capacidad organizativa del partido para llevar adelante desfiles y mítines de manera coordinada y redoblar el número de conferencias en tiempos de actividad proselitista. Destacaba el protagonismo de los oradores, pero más bien subrayaba el uso de nuevas técnicas -la "propaganda luminosa», por ejemplo-,

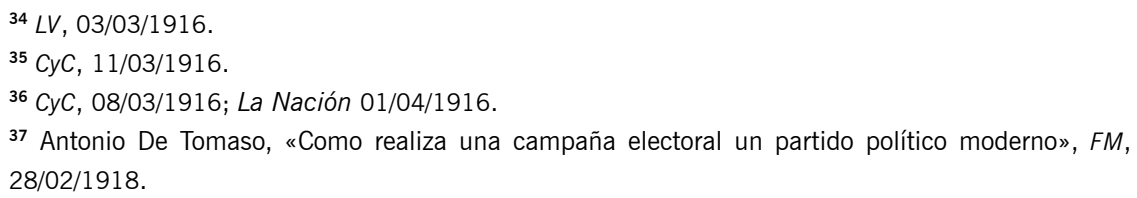


con las que se seducía a la audiencia. Gracias a la «linterna mágica», explicaba, el PS atraía la mirada de la multitud hacia pantallas en las que se proyectaban «leyendas breves y concisas». En dos páginas con fotografías en cuidadosa armonía con el texto, su artículo mostraba a un partido que había comprendido el arte de la propaganda política en términos modernos.

De Tomaso construía una explicación sofisticada, pero parcialmente verdadera. En primer lugar, su interpretación daba escasa atención al pasado partidario, es decir a la experiencia adquirida por el ps en casi dos décadas de participación en la vida pública. Es verdad que el socialismo se lanzó a una campaña de una escala inusitada y bajo una normativa que desconocía precedentes. No obstante, también era cierto que ya había acumulado una práctica en materia de actividades proselitistas y de usos políticos del espacio público, que pudo y supo capitalizar. Aquí hemos intentado demostrar que parte de esa historia y también mucho de esa capacidad de despliegue proselitista se debió al protagonismo de las mujeres. $\mathrm{Y}$ esto era posible, tal como hemos insistido, precisamente porque las formas de movilización y participación en el espacio público - motorizadas en muchos casos por demandas sociales- se articularon con y nutrieron, a su turno, a aquellas de la vida electoral. Para 1916, el Ps contaba con un repertorio nutrido y aceitado para la actividad proselitista. Y, si tomamos en cuenta los estudios dedicados a la financiación de la política (MAURO y LICHTMAJER, 2OI4), comenzamos a advertir que éste probaba ser útil, en ocasiones, para la recaudación de fondos que, aunque muy probablemente modestos, podían contribuir a afrontar los gastos que implicaban las campañas electorales. En ese camino recorrido se habían formado oradores y también oradoras y un público diverso -de hombres y mujeres de distintas edades- se encontraba acostumbrado a la prédica de voces femeninas.

A la luz de esta historia, la incesante labor de Begino en el verano de i9ı6 no resultaba excepcional. Ella misma había disertado públicamente en ocasiones anteriores y otras mujeres, antes que ella, se habían desenvuelto con comodidad en la tribuna. Su concurso en la campańa presidencial evidenciaba cuanto podía maximizarse esa experiencia en un contexto electoral novedoso, marcado por la competencia limpia entre partidos. Ilustraba también que en el ps la vida electoral podía mantener cierto margen de heterosexualidad pese a que la nueva ley de I9I2 no había hecho sino masculinizar su ejercicio.

En segundo lugar, en su artículo, De Tomaso ponía énfasis en el protagonismo de los hombres del Ps, en sus previsiones y empeño para organizar una empresa 
política y cultural alternativa y moderna. Sin embargo, poco decía sobre el uso que los socialistas hacían de otros canales de comunicación, entre ellos la prensa comercial. Este silencio era paradójico, sobre todo porque su artículo se publicaba justamente en uno de esos célebres magazines. Si los semanarios ilustrados de circulación masiva en las primeras décadas del siglo xx representan un corpus documental tan útil como fecundo para aproximarnos al estudio de la política electoral, en general, y a los protagonistas de esta primera campaña presidencial del ps, en particular, esto obedece y, en si mismo documenta, la existencia de una relación -al parecer estrecha- entre la prensa no partidaria y los/las militantes ${ }^{39}$. Y como lo ilustra la mirada sobre las socialistas en su labor proselitista, particularmente sobre Begino, esta atención nacía de una conjunto de factores: su interés por la política, la abierta simpatía de algunos de los periodistas o informantes por el socialismo; la decisión de estas revistas de publicar escritos de los propios dirigentes partidarios, y el hecho no menor de que algunos de esos hombres y también mujeres se habían convertido en colaboradores, relativamente asiduos, de esos semanarios. Aunque, como confesaba Begino, ella debía confiar en su oficio manual para sobrevivir, su trayectoria advierte que vale la pena avanzar en un estudio en profundidad sobre los vínculos entre prensa de masas, socialismo y mujeres, en su doble condición de escritoras y militantes.

Una narrativa de la campaña presidencial no puede desatender las buenas razones esgrimidas por la dirigencia partidaria, que no por ser parciales eran menos verdaderas. Claro que, al privilegiar el análisis del protagonismo femenino se puede ser sensible no simplemente a la presencia de otros actores, sino también al modo en que se revitalizaron y resignificaron las prácticas decimonónicas de participación en el espacio público y electoral al servicio de una política de masas. Se puede advertir, asimismo, la centralidad que para el ps adquirió la prensa comercial como medio para transmitir su mensaje, hacer conocer sus protagonistas, dotar de relevancia y multiplicar esas palabras e imágenes de las mujeres socialistas en tiempos de campaña electoral.

${ }^{39}$ Respecto a la relación de la izquierda y la prensa comercial resulta orientadora la interpretación de Laura Beers para el caso de Gran Bretaña (BEERS, 2009). Sobre el socialismo, la prensa y la cultura de masas, ver BUONUOME (2016); sobre la posición de los socialistas ante las industrias culturales y los espectáculos deportivos, cfr. GUIAMET (2016 y 2018). 


\section{Referencias bibliográficas}

ARIZA, JULIA (2009): «Bellezas argentinas y femmes de lettres. Representaciones de la mujer en la revista ilustrada Plus Ultra (1916-1930)», en: L. Malosetti Costa y M. Gené (eds.), Impresiones porteñas. Imagen y palabra en la historia cultura de Buenos Aires, Buenos Aires, Edhasa, pp. 81-108.

BARRANCOS, DORA (1994): «Entre la celebración y el escarnio: mujeres contestatarias (1890-1900)", en: L. Fletcher (comp.), Mujeres y cultura en Argentina del siglo XIX, Buenos Aires, Seminaria. BARRANCOS, DORA (2005): «Socialismo y sufragio femenino. Notas para su historia (1890-1947)», en: H. Camarero y C. Herrera (comps.), El Partido Socialista en Argentina. Sociedad, política e ideas a través de un siglo, Buenos Aires, Prometeo, pp. 159-184.

BARRANCOS, DORA (2007): Mujeres en la sociedad argentina. Una historia de cinco siglos, Buenos Aires, Sudamericana.

BECERRA, MARINA (2009): Marxismo y feminismo en el primer socialismo argentino. Enrique del Valle Iberlucea, Rosario, Prohistoria Ediciones. BEERS, LAURA (2009): «Education or Manipulation? Labour, Democracy and the Popular Press in Interwar Britain», en: Journal of British Studies, vol. 48, no 1, pp. 129-152.

BERENSZTEIN, SERGIO (1991): Un partido para la Argentina moderna. Organización e identidad del Partido Socialista (1896-1916), Buenos Aires, CEDES.

BUONUOME, JUAN (2015): «Fisonomía de un semanario socialista: La Vanguardia, 1894-1905», en: Archivos de historia del movimiento obrero y la izquierda, $n^{\circ}$ 6, pp. 11-30.

BUONUOME, JUAN (2016): Periodismo militante en la era de la información: La Vanguardia, el socialismo y los orígenes de la cultura de masas en la Argentina (1894-1930), Tesis de doctorado, Universidad de San Andrés.

CARUSO, LAURA (2018): «La huelga, el carnaval y Ios comicios: el mundo del trabajo portuario en Buenos Aires y la configuración de una comunidad obrera, verano de 1904», en: Historia Crítica, $n^{\circ}$ 71 (en prensa).

EUJANIAN, ALEJANDRO (1999): Historia de revistas argentinas, 1900-1950: la conquista del público. Argentina, Buenos Aires, Asociación Argentina de Editores de Revistas.

GALLO, EDITH ROSALÍA (2001): Las mujeres en el radicalismo argentino 1890-1991, Buenos Aires, Eudeba.

GENÉ MARCELA Y BUONUOME, JUAN (2013): «Consumidores virtuosos. Las imágenes publicitarias en el diseño gráfico de La Vanguardia (1913-1930)», en: L. Malosetti Costa y M. Gené (comps.), Atrapados por la imagen. Arte y política en la cultura impresa argentina. Buenos Aires, Edhasa, pp. 137-164. GONZALEZ ALEMAN, MARIANNE (2014): «Ciudadanos en la calle. Violencia, virilidad y civilidad política en la campaña presidencial porteña de 1928», en: Hispanic American Historical Review, vol. 94, no 3, pp. 421-453.

GUIAMET, JAVIER (2016): «El trompeador Firpo. El boxeo dentro del imaginario del socialismo argentino de los años veinte», Anuario de la Escuela de Historia Virtual, no 9, pp. 61-80.

GUIAMET, JAVIER (2018): «CCultura en los fields» Socialismo y fútbol en la Argentina de los años veinte», en: Nuevo Mundo/Mundos Nuevos. Puesto en línea el 14 junio 2018. Disponible en: http://journals.openedition.org/nuevomundo/72149 (último ingreso: 10/09/2018).

HOROWITZ, JOEL (2015): El Radicalismo y el movimiento popular (1916-1930). Buenos Aires, Edhasa. 
KIRKPATRICK, GWEN (1990): «The journalism of Alfonsina Storni: A new approach to women's history» en: AAVV, Women, Culture and Politics in Latin America, Berkeley, University of California Press, pp. 105-129.

LAVRIN, ASUNCIÓN (1995): Women, Feminism, and Social Change in Argentina, Chile and Uruguay, 1890-1940, Lincoln, University of Nebraska Press. LOBATO, MIRTA (2018): "Escenas de lo social en publicaciones de circulación masiva: Caras y Caretas (1898-1930)», en: R. González Leandri y J. Suriano (eds.), La cuestión social y sus itinerarios de difusión a través de las publicaciones periódicas argentinas, 1870/1930. Rockville, Global South Press

LOBATO MIRTA ZAIDA Y PALERMO, SILVANA A. (2011): «Del trabajo a las calles: dignidad, respeto y derechos para los y las trabajadoras», en: M. Lobato (ed.), Buenos Aires: manifestaciones, fiestas y rituales en el siglo XX, Buenos Aires, Editorial Biblos, pp. 45-74.

MARTINEZ MAZZOLA, RICARDO (2015): «iMales pasajeros? El Partido Socialista frente a las consecuencias de la Ley Sáenz Peña», en: Archivos de historia del movimiento obrero y la izquierda, $\mathrm{n}^{\circ}$ 6, pp. 53-72.

MAURO, DIEGO Y LICHTMAJER, LEANDRO (2014): LOS costos de la política. Del Centenario al primer peronismo. Buenos Aires, Imago Mundi.

NEWMAN, KATHLEEN (1992): «The modernization of femininity: Argentina, 1916-1926» en: AAVV, Women, Culture and Politics in Latin America, Berkeley, University of California Press, pp. 74-89. PALERM0, SILVANA A. (2016): «Tribunas y panfletos: la primera campaña presidencial del Partido Socialista bajo la ley Sáenz Peña», en: Estudios, $n^{\circ}$ 35, pp. 37-56.

PALERM0, SILVANA A. (2018): «La lotería electoral: la primera campaña presidencial bajo la ley Sáenz Peña en las revistas ilustradas (Argentina, 1916)», en: S. Gayol y S.A. Palermo (comps.), Política y cultura de masas en la Argentina de la primera mitad del sig/o XX, Ediciones UNGS, 2018.

PARTIDO SOCIALISTA (1915): Versión Taquigráfica del II Congreso Extraordinario (XIV Congreso Nacional), 9, 10 y 11 de julio de 1915 en la Capital Federal, Buenos Aires, s/d.

POY, LUCAS (2017): «Las intervenciones electorales del Partido Socialista en la ciudad de Buenos Aires antes de la Ley Sáenz Peña (1896-1910)», en: Sociohistórica, $\mathrm{n}^{\circ} 39$.

QUEIROLO, GRACIELA (2016): «Dobles tareas: Ios análisis de Josefina Marpons sobre el trabajo femenino en la década de 1930", en: Anuario de la Escuela de Historia Virtual, nº 9, pp. 81-97. REYES, FRANCISCO J. (2016a): «De la velada de club a la estética de los cortejos: La construcción del $1^{\circ}$ de Mayo socialista en la Argentina finisecular (1894-1900)», en: Boletín del Instituto de Historia Argentina y Americana «Dr. Emilio Ravignani», n 44, 42-77.

REYES, FRANCISCO J. (2016b): «El aprendizaje de las calles. Los socialistas y las manifestaciones políticas en la Argentina finisecular (1894-1901)», en: Foros de Historia Política. Disponible en: http:// historiapolitica.com/datos/foros/foroordenreyes. pdf (último ingreso: 09/11/2018).

RAITER, BÁRBARA (2004): Historia de una militancia de izquierda. Las socialistas argentinas a comienzos de sig/o XX, Centro Cultural de la Cooperación. Ediciones del Instituto Movilizador de Fondos Cooperativos. Buenos Aires.

REY, ANA LíA (2011): «Palabras y proyectos de mujeres socialistas a través de sus revistas (19001956)», en: Mora, no 17.

ROGERS, GERALDINE (2008): Caras y Caretas: Cultura, 
política y espectáculo en los inicios del siglo XX argentino, La Plata, EDULP.

ROJKIND, INÉS (2008/2009): «El malestar obrero». Visibilidad de la protesta social en Buenos Aires del novecientos», en: Travesía, n 10-11, pp. 15-44. ROSANVALLON, PIERRE (1999): La consagración del ciudadano. Historia del sufragio universal, Instituto Mora, México.

SANDERS, ELIZABETH (2015): «The war and peace election of 1916», en: G. Davis y J. Zelinger (eds.), America at the ballot box. Elections and political history, Philadelphia, University of Pennsylvania Press.

SCOTT, JOAN (2012): Las mujeres y los derechos del hombre. Feminismo y sufragio en Francia, 1789-1944, Buenos Aires, Siglo XXI.

TARCUS, HORACIO (dir.) (2007): Diccionario Biográfico de la Izquierda Argentina, Buenos Aires, Emece. TOSSOUNIAN, CECILIA (2013): «Images of the Modern Girl: From the Flapper to the Joven Moderna
(Buenos Aires, 1920-1940)», en: Forum for Interamerican Research, vol. 6, pp. 41-70.

VALDÉZ, MARÍA JOSÉ (2012): «El Plebiscito de Hipólito Yrigoyen: La campaña electoral de 1928 en la ciudad de Buenos Aires vista desde La Época», en: Población y Sociedad, vol. 19, n 1, pp. 75-103. VALDÉZ, MARÍA JOSÉ (2014): «Algunas hipótesis sobre los mecanismos de financiamiento político de la Unión Cívica Radical. Las campañas electorales de 1928 y 1930 en la ciudad de Buenos Aires», en: D. Mauro y L. Lichtmajer (comps.), Los costos de la política. Del Centenario al primer peronismo, Buenos Aires, Imago Mundi, pp. 41-58. VALOBRA, ADRIANA MARÍA (2010): Del hogar a las urnas. Recorridos de la ciudadanía política femenina. Argentina, 1946-1955, Rosario, Prohistoria. WALKER, RICHARD (1977): The Socialist Party of Argentina, 1890-1930, Austin, The University of Texas Press. 